\title{
CHAINS OF CONNECTION: RETHINKING THE BOURGEOISIE*
}

\section{THEODORE KODITSCHEK}

Department of History, University of Missouri

E-mail: koditschekt@missouri.edu

Since his first year in graduate school, Jerrold Seigel has puzzled over the relationship between modernity and the bourgeoisie. Willing to acknowledge the salience of this class in the making of the modern, he grew increasingly troubled by the failure of every effort to give a clear account of its distinctive historical role. To define the bourgeoisie as simply the group(s) in the middle, "all those who are neither peasants nor workers on the one side, nor aristocrats by birth on the other," might be empirically accurate, he reasoned, but this provided no analytical insight into the processes of history. The Marxist alternative avoids this vacuity, but only by creating a mythology of the ascendant bourgeoisie-a class that by mere dint of its privileged relation to capital is deemed to be capable of entirely transforming the realms of culture, politics, and the material world. Dissatisfied with these conventional approaches, Seigel introduced a fundamentally new way of thinking in his seminal synthesis Modernity and Bourgeois Life, which sought to replace the "traditional nominative formulation [of the bourgeoisie's role] with ones that are more adjectival and historical." Considering "'bourgeois', not in terms of the rise of a class," he has reconceptualized this term to denote "the emergence and elaboration of a certain 'form of life'." It is in connection with this project that Seigel developed the two key concepts that will be considered in this essay, "chains of connection" and "networks of means" $(M B L, \mathrm{ix}, 6,25) .{ }^{1}$

I would like to thank Katelyn Ball for her comments and suggestions on the penultimate version of this essay.

1 I hope that a clear understanding of these two terms will emerge in the course of this essay. Suffice it to say here that they are integrally related: the first denotes the circumstances opened up, under conditions of modernity, whereby individuals become connected to others who were previously distant from them in consanguinity, community, and space. The second references the activities through which individuals exploit these connective chains to advance their autonomous ends. It is central to Seigel's argument that enhanced networks of means can enable such individuals to further extend their chains 
I

In Seigel's rendering, the possibility for establishing "chains of connection" opened up unevenly and differentially in various European countries during the early modern period with the declining power of "teleocratic" institutions and networks, such as the Church, guilds, and the monarchical state, which sought to monopolize power for some transcendent ulterior purpose. ${ }^{2}$ With the weakening of these established institutions and networks a space was opened up for individuals to establish new chains of connection to serve their own "autonomous" ends. It is through these chains of connection, in Seigel's probing analysis, that individuals with sufficient economic, cultural, and political resources were able to establish "networks of means" that enabled them to amplify their assets and opportunities in each of these three spheres. It was out of the increasing density of such networks, during the nineteenth century, that the fabric of "bourgeois life" emerged.

Seigel envisions these "networks of means" emerging unevenly in three distinct but interdependent spheres. (1) Through the spread of markets and money relations, and the exchange of material goods, networked people were able to establish relationship chains with others who were far distant in occupation and space. (2) Through the spread of new means of communication and information sharing, they were able to exchange ideas and cultural practices with other networked individuals outside their local communities. (3) Through new political relationships and the increasing power of the sovereign state, those who were incorporated in enhanced political networks were able to leverage their influence and opinions to a degree that would have been inconceivable during any previous historical era. In each case, the networks of meanseconomic, cultural, and political-entailed the abstraction of hitherto concrete commodities, power relationships, and cultural practices. Through networking, social connections that had formerly been embedded in personal bonds were opened up to encounters that were no longer scripted or predetermined. This quest for more autonomous forms of connection necessitated a more "abstracted" reconceptualization of the materials, concepts, and practices that were being exchanged. In this manner, goods, ideas, and powers that had previously been confined to local settings could be unleashed in more universal processes to fabricate a densely networked bourgeois world.

of connection, which then precipitates a self-reinforcing process of mutual expansion and empowerment for both chains and networks together.

2 Seigel defines "teleocratic networks" as those in which "flows through them were directed by some end outside themselves." He sees them as "characteristic of an age or a culture in which social life was thought to be ordered by a transcendent or inherited hierarchy of values and functions" $(M B L, 18)$. 
Seigel does not deny that the creators and beneficiaries of these "networks of means" were disproportionately bourgeois in terms of their class location. He simply resists associating this innovative social form with the project of any particular class. Many members of the eighteenth- and nineteenth-century bourgeoisie remained attached to traditional teleocratic goals and institutions. At the same time, the new networks were open to enlightened members of the aristocracy. Eventually, certain sectors of the working class also learned to access such networks. It was this trans-class dimension that gave the advent of networks their transformative power. Moreover, the process played out differently and unevenly in the three national settings attended to by Seigel. In Britain, it was economic networks that drove the dynamic forward, with political and cultural networks following in their wake. In France and Germany, it was political and informational networks that gained primacy, with economic networks following belatedly. Through different paths, however, all three of Europe's three major nation-states had, by the end of the nineteenth century, become effectively functioning network societies.

To fully understand the power of Seigel's historiographical reconceptualization, it is necessary to recognize that his notion of "networks" actually had its origin in his previous publication, his penetrating study of The Idea of the Self. Of course, Seigel never claims that notions of the self were entirely absent during premodern epochs. He simply argues that the new experiences of modernity gave the self a solidity and subjective autonomy that it had hitherto lacked. As Europe was transformed by new social relationships during the early modern period, cognitive reflection on these relationships, and on the bodily experience of corporeality, endowed at least the series of high intellectuals whom he studied with an enriched understanding of their capacities for autonomy. Seigel takes issue with simplistic accounts of the modern self, such as that of Charles Taylor, which would characterize it as disengaged from the social (understood largely as communitarian) world. On the contrary, in Seigel's view the modern self was the product of dialectical interaction between three dimensions of the experience of selfhood: the social, the corporeal, and the reflective-the last being a kind of meta-self that processes the selfhood of corporeal and social experience. Seigel's argument is simply that modern conditions greatly intensified this dialectical interaction between the three levels, creating at least some individuals with a sense of autonomy that was sufficient (and sufficiently grounded) to enable them to access the new opportunities for a "network of means."

Since The Idea of the Selfis a work of high intellectual history, Seigel focuses on a string of canonical thinkers who grappled with the problem of modern selfhood at a high level of abstraction. Here, he distinguishes those, like John Locke and Adam Smith, who understood the self as the product of experience in multiple (all three) dimensions, from those, like Descartes and Leibniz, who sought to apprehend 
it primarily at the meta-level, through self-apprehension in the "reflective" realm. This parallels the critique he offered earlier, in his biography, Marx's Fate, which diagnosed a comparable solipsism in that preeminent philosopher of the "social," precisely because Marx had excessively privileged the social dimension of modern selfhood, and became therefore paradoxically committed to a theoretical framework that apprehended it in an excessively reflective and teleological way. In Seigel's account, it is Adam Smith who offers the first fully balanced account of three-dimensional modern selfhood, opening the way to a full understanding of its relation to "chains of connection," and therefore of its ability to begin constituting "networks of means." In The Wealth of Nations, Smith explored the process whereby market exchange enabled individuals to increase the productivity of their labor and to maximize satisfaction of their consumer desires by abstracting material commodities via the medium of money relationships (what Marx would later disparage as "the fetishism of commodities") that enabled them to create de facto social connections with strangers at vast distances everywhere around the world. In the Theory of Moral Sentiments, Smith created a parallel theoretical framework for understanding ethical intersubjectivity in a comparable frame. By projecting their own behavior in the imaginary person of the "impartial spectator," individuals were able to abstract their unique personal imperatives and compulsions into socially acceptable, universal forms, which facilitated confidence that distant strangers might be expected to act in trustworthy ways. ${ }^{3}$

In both cases, Seigel sees Smith's breakthrough intellectual accomplishment as grounded in his embeddedness in British society, where such abstracted chains were already in operation, and individuals were already channeling them into "networks of means" that simultaneously enriched society while also benefiting themselves. Both in the realm of ethics, and that of economics, the Smithian autonomous self had found a way of simultaneously benefiting both the individual and the larger society. By contrast, in France and Germany, where such chains and networks remained underdeveloped, seminal thinkers who tried to theorize them, most notably Rousseau and Hegel, were unable to break entirely from teleological ways of thinking because they remained embedded in still fundamentally teleocratic societal worlds. For this very reason, however, Seigel suggests, they provided indispensable theoretical guides for the mobilization of their countrymen, who came to see that through the establishment of "chains" and "networks" in the realm of reform or revolutionary politics, it might be possible to dislodge existing Old Regime establishments and create new,

Adam Smith, The Theory of Moral Sentiments (Oxford, 1976; first published 1759); Smith , The Wealth of Nations (New York, 1937; first published 1776). 
republican spaces of intersubjectivity that would facilitate the development of future chains and networks in the economic and ethical realms.

II

Having established this basic analytical framework through his analysis of leading intellectuals in The Idea of the Self, Seigel was ready, some seven years later, in Modernity and Bourgeois Life, to extend a more fully articulated "chain" and "network" analytic to a broader understanding of nineteenth-century European economic, cultural, and social history. Greatly (perhaps excessively) influenced by a generation of historiography that has emphasized a slower, more incremental pattern of European economic development and social transformation, Seigel concludes that in all three of the countries that he examines, full scope for the chains and networks of the new bourgeois order did not open up until the decades after 1850 . During that period, the spread of the railroad, the steamship, and new communications technology finally broke down the surviving remnants of the old local, teleocratic order, and made space for an economy of industrial development and a politics of autonomous organization.

In Britain, the advance was muted by the legacy of early investment in manufacturing technology and political alliances that were soon to be antiquated. In France, however, the advent of Crédit Mobilier, railway construction, and the rebuilding of Paris created a breakthrough to incipient industrialization, the breakdown of local and regional isolation, and the rise of a truly national economy. After 1870, the establishment of the Third Republic brought an end to the conflict of rival teleocratic political regimes, and facilitated the rise of modern mass democratic parties. In Germany, the path towards national unification brought a veritable economic revolution in its wake. State sponsorship of science, technical education, and entrepreneurship unleashed industrial transformation on a scale that was historically unprecedented. Although state power itself was retained in authoritarian hands, mass parties developed here, as elsewhere, although it was social democrats, rather than liberals, who took fullest advantage of this trend. Notwithstanding these important political differences, national experiences in Western Europe were steadily converging, generating nation-states in which the bourgeoisie did not necessarily exercise class domination, but which were increasingly suffused with network-friendly bourgeois life-worlds.

One of the most impressive features of Seigel's analysis is his exposition of the vast infrastructure - set in place during the 1870 os and 1880s - that was necessary for the chains and networks of bourgeois life to pass the threshold into full abstraction, and thereby to transcend the limitations of preexisting local milieus. Without the standardization of uniform time (Greenwich Mean Time from 1884), the new networks of rail and telegraphic communication would have broken 
down. Paper money had to be correspondingly standardized by the big quasipublic national banks to supplant older systems of credit by private banks and locally issued bills of exchange. Only then could chains and networks that had hitherto been limited by personal relations be expanded on a truly national or international scale. With the simultaneous mechanization of several large-scale industries (steel, chemicals, electricity, agriculture, transport, and machine tools), labor productivity began to skyrocket in ways that belied both the pessimism of classical political economy and the revolutionary theories of Karl Marx. As anticipated limits to the augmentation of surplus value were quickly surpassed, "iron laws" about declining profits were hastily abandoned and the resilience of modern capitalism became evident to all.

By conceptualizing the abstractions of capital through his interpretive lens of autonomous networks (especially networks of money and information), Seigel is able to shed intriguing light on many features of the late Victorian epoch. In terms of gender, it contributed to new opportunities for women, who were now positioned to break out from the confinement of "separate spheres" which had formerly restricted network autonomy to men alone. This had further implications for the opening of sexual expression, as erotic impulses that had hitherto been restrained by the imperatives of family respectability could be allowed a freer and wider circulation. As men and women found new careers through more impersonal channels they were empowered to live their lives in more autonomous ways. For artists, musicians, and writers, there were new opportunities for cultural purveyance, in which impresarios mediated access to larger, more diverse audiences, breaking the power of traditional aesthetic arbiters, and laying the foundations in one direction for a consumer-driven cult of the classics, in another direction towards an artist-driven avant-garde.

Of course, there were dangers in this new world of individuation and autonomy, which could be perceived as potentially anarchic, chaotic, isolating, or immoral, promoting personal excess and masturbatory fantasy. For at least one group, the Jews, this universalization of autonomy might even be construed as foreshadowing disaster, since it undercut their formerly unique role as the traditional network people. In the old teleocratic world where they held a nearmonopoly on chains and networks, the Jews had been simultaneously alien and indispensable, whereas now they had become aliens who might be all too easily disposed. The obvious solution of assimilation was, indeed, embraced by many, but this sparked a backlash of populist resentment among certain sectors of the Christian masses that would have all-too-murderous consequences in the twentieth century. ${ }^{4}$ Nevertheless, when it comes to "the culture of means" 
authorized by the universalization of networks, Seigel is disinclined to dwell on the darker side. He duly acknowledges that the expansion of bourgeois culture did create some new class divides between the middle-class devotees who were directly caught up in it and certain sectors of the working class that were left behind. Nevertheless, his analysis insists that "bourgeois life" was not classrestrictive, and he details the many ways in which working people were drawn up in distant chains of connection and autonomous networks of means that were analogous to, or interconnected with, the chains and networks of those above them in the social scale.

\section{III}

I hope it is obvious to any reader who is unfamiliar with Seigel's oeuvre that his accomplishment should be acknowledged as a tour de force. If books like Marx's Fate, Bohemian Paris and the Idea of the Self deserve to be ranked as classics of intellectual history, Modernity and Bourgeois Life represents a major breakthrough in the social history of ideas. Seigel had long been working towards his own fusion of social with intellectual history, and in Modernity and Bourgeois Life the incipient genre comes into its own. In this regard it offers a marked and bracing contrast to the veritable library of post-structuralist tomes deploying discourse analysis, which, over the last generation, have tried to convince us they are presiding over of the death of the subject. We can duly agree that discursive structures frame the ways in which humans apprehend reality and limit the terms within which we communicate with others about its meaning. Yet "discourse" does not blindly dictate the forms of its utterance, and the most insightful exemplars of this type of intellectual history-for example the history of political thought in the Pocockian tradition — command our attention through the ways in which they invoke a dialectic between the discourse community in which a given thinker is embedded, and the ways in which he (shes are rarely noticed) alters textual formulation, in either minor or consequential ways. ${ }^{5}$ While Seigel is equally respectful of the integrity of ideas, his approach takes us two steps

ran against the grain of the Christian telos, and then found itself in an ambiguous position during the nineteenth century, when the general break with teleocracy left its members under suspicion as being national aliens, stuck in a backward telos of their own. By identifying Jewish networks with state finance, Seigel sees support for decentering capitalism from the bourgeois experience. But how, then, do we explain popular antiSemitism, since the typical Jew encountered by the typical peasant was not a petty Rothschild, but a petty peddler, whom he would be likely to despise on class, as much as on cultural, grounds?

5 The classic example is J. G. A. Pocock, The Machiavellian Moment: Florentine Political Thought and the Atlantic Republican Tradition (Princeton, 1975). 
further into the terrain of the social historian, (1) by reintroducing human agency into the discussion, and (2) by taking it for granted that alterations in discursive formulation will be at least partly occasioned by changes that have transpired in socioeconomic and material life. ${ }^{6}$

In my view, the single most compelling feature of Seigel's chains/network perspective is the way it reconnects capitalism with bourgeois life. So, for example, he insists on associating Marx's famous pronouncement about "constant revolutionizing the means of production" with the constant revolutionizing of aesthetics undertaken by the avant-garde. Consequently, far from being inherently antithetical, bourgeoisie and Bohemia are two poles of the same process of "creative destruction," in which "all fixed, fast-frozen relations ... are swept away ... All that is solid melts into air ... [and] man is at last compelled to face with sober senses, his real conditions of life and his relations with his kind" (MBL, 482-525; Marx quote at 483)..$^{7}$ Of course, for Seigel, unlike for Marx, "capitalism" and "bourgeois life" are intersecting rather than identical sets. This insight corrects one of the major deficiencies in Marxism and helps us to understand why, in spite of the manifold (and continuing) "contradictions within capitalism," its chains of connection have consistently dragged us ever deeper and deeper into the ever-thickening networks of bourgeois life.

Nevertheless, in his effort to distance himself from the deficiencies of Marxism, Seigel has taken his critique one step too far, in my opinion. This becomes apparent when we look more closely into the three variants of "network"-economic networks grounded in money, cultural networks grounded in information, and political networks grounded in the centralized state- that form the core of Seigel's conceptualization. In terms of clarity of formulation and coherence of elaboration, these three are not exactly comparable, in my view. Seigel invokes the inspiration of Simmel in his formulation of economic networks ( $M B L, 6-7,29-30)$, but, as he is well aware, behind Simmel's Philosophy of Money lies the dialogue on the nature of commodities between Smith and Marx. ${ }^{8}$ Notwithstanding their many differences, Smith and Marx both agree that the social significance of money is not sui generis, but derives from the way it offers a medium of exchange and generalization that enables

6 For a flavor of the debate on postmodernism in history see Keith Jenkins, ed., The Postmodern History Reader (London, 1997); and Joan Scott, Gender and the Politics of History (New York, 1988). Seigel offers his own critique of Foucault and Derrida in IS, 603-50.

$7 \quad$ On capitalism as "creative destruction" see Joseph A. Schumpeter, Capitalism, Socialism and Democracy (New York, 1950; first published 1942), 81-7.

8 Georg Simmel, The Philosophy of Money, trans. Tom Bottomore and David Frisby (London, 1990; first published 1900). 
concrete objects (use values) to be transmuted into universal, abstracted forms. It is this that enables them to constitute the chains and networks that bring farflung (autonomous) individuals into social relations with one another although they have never overtly cooperated, or often even met. Here, the network concept strikes me as very clear and logically consistent, lending its underlying coherence to Seigel's somewhat more problematic second and third network forms, which would not necessarily be very persuasive on their own.

When we come to Seigel's cultural networks, grounded in abstractly exchangeable information, it seems to me that the same degree of logical coherence is lacking. Insofar as there is a theoretical foundation to this concept, it seems most likely to come from Smith's Theory of Moral Sentiments. Nevertheless, here, as Smith himself recognized, the grounding is a good deal less secure than in The Wealth of Nations. Where economic exchange can be rooted entirely in selfinterest, social sympathy requires a more projective "benevolence," which can be anticipated only if the "impartial spectator" is at large. ${ }^{9}$ In some circumstances, there is a good deal of evidence for the success of such operations, for example, in the "Republic of Letters" that invisibly knit early modern European intellectuals together in a chain of interconnected (and mutually interactive) intellectual inquiry (see $M B L, 9-10,19,537-41$ ). Similar patterns can perhaps be found in the host of religious and secular voluntary associations that came to thicken nineteenth-century Europe's burgeoning urban landscapes. Yet such entities often proved to be rather weak and evanescent. When they survived, they often hardened into institutional bodies that came to resemble the oligarchical or teleocratic establishments of the Old Regime. ${ }^{10}$ It certainly seems telling that today's "Republic of Letters" appears wholly encased in the iron cage of the modern research university, where "autonomous" networkers find themselves constrained by administrative bureaucrats, granting foundations, regulatory agencies, tenure procedures, student expectations, pandering politicians, and a skeptical public which has grown increasingly resistant to paying for what we do. ${ }^{11}$

When it comes to political networks, grounded in the centralizing state, I feel that the conceptual ambiguities are even more pronounced. Here Seigel's evidence for "networks" focuses on two areas: (1) the interacting webs of officials (especially reform-minded German/Prussian state civil servants) and (2) the participation of enfranchised (or semi-enfranchised) citizens through

9 Smith, The Theory of Moral Sentiments, 3-29; Smith, The Wealth of Nations, 9-26, 43-50, 78-91, 321-7.

10 See, for example, my own Class Formation and Urban Industrial Society: Bradford, 1750-1850 (Cambridge, 1990).

11 John McGee, Breakpoint: The Changing Marketplace for Higher Education (Baltimore, 2015); Goldie Blumenstyk, American Higher Education in Crisis? (Oxford, 2015). 
electoral party politics, whereby individuals leveraged their political aspirations into organized collective action that was designed to leave its imprint on government policy. Seigel provides considerable specific evidence to support the salience of both instrumentalities in forging a new realm of autonomous civic activity, especially in France and Germany where teleocratic authoritarianism remained enthroned. ${ }^{12}$ Nevertheless, it seems important to note that these two instrumentalities represented networks of very different types, which operated at different levels, and often in incommensurable ways. Networking with one another when they could, state officials remained subordinate servants, ultimately dependent on the policy directions that were handed down from on high. ${ }^{13}$ Mass parties might have started out as genuinely autonomous organizations, yet even the most democratic-minded underwent a tendency to become dominated by oligarchies and party bosses. Eventually, they became cogs in the wheel of twentieth-century "managed democracy," formulating party platforms, selecting narrowed ranges of appropriate candidates, and propagandizing rank-and-file party members to pitch their politics in a particular way. ${ }^{14}$

None of these strictures are intended to cast doubt on the general validity of Seigel's network analysis. My point is rather to suggest that his cultural and political networks are somewhat loose formulations, whose plausibility in large measure depends on the degree to which they mirror, along with informational and political goods, a set of abstracting market exchanges that have their roots in the economic sphere. If this is correct, then I think we must acknowledge that the entire nexus of autonomous networks has its roots in the economic system of commodity capitalism to a much greater extent than Seigel's tripartite presentation allows. Seigel is right to insist that the "bourgeois life" he is trying to capture is not reducible to the ideology of any single specific class. Yet when Marx and Engels claim that the bourgeoisie "creates a world after its own image"

12 In general, I find Seigel's analysis of the state as a container for administrative and/or civic networks to be the most forced and problematic portion of his book. In my view, we must see states first and foremost as institutions (indeed, they are sovereign institutions par excellence). In contrast to networks, institutions such as states are governed primarily by rules, roles, ulterior goals, and internal hierarchies even in the modern age. Where Seigel envisions citizenship as an exchange token, I think it is much more illuminating to see it as a ticket for political inclusion. See, for example, Ernest Gellner, Nations and Nationalism (Ithaca, 1983), 1-7, 53-87; Benedict Anderson, Imagined Communities: Reflections on the Origin and Spread of Nationalism (London, 2006; first published 1983), 5-7; Eric Hobsbawm, Nations and Nationalism since 1789 (Cambridge, 1990), 1-100.

13 John R. Gillis, The Prussian Bureaucracy in Crisis, 1840-1860 (Stanford, 1971).

14 Moisey Ostrogorski, Democracy and the Organization of Political Parties, vol. 1, England (Chicago, 1964; first published 1902); Robert Michels, Political Parties: A Sociological Study of the Oligarchical Tendencies of Modern Democracy (New York, 1962; first published 1915). 
within capitalism, I believe that their analysis is consistent with what Seigel is trying to do. One of the curious features of Seigel's presentation is the relative brevity of his substantive discussion of class. While he offers reassurance that there remains a legitimate place for class analysis in the kind of history he is writing, he has little to say about what that place would be. ${ }^{15}$ Most of his substantive critique of Marxist exaggerations of class determinism comes in a discussion of the class interpretation of the French Revolution - an interpretation that is today questioned even by many Marxists, and is not really relevant to the question of nineteenth-century industrial capitalism, which constitutes the major focus of his book. ${ }^{16}$

Seigel is right to insist that the industrial proletariat was not by definition excluded from the informational or political networks of bourgeois existence, and that-as consumers and small property owners-many eventually acquired a stake in the market economy as well. What his account neglects is how long and how deeply most working people remained excluded by poverty, ignorance, insecurity, ill health, and disenfranchisement from accessing the existing "cultures of means" that were available to their social betters. ${ }^{17}$ A similar caution might be issued to flag his discussion of the emancipation of women, and the decline of separate spheres. It is, of course, true that the advent of feminism and the "New Woman" in the 1880 ond 1890 os can be taken as evidence that some middle-class women were gaining access to autonomous networks. Still, the fact that many of their goals were not achieved until the second feminist wave, a century later, suggests that the decline of patriarchy was a long, protracted process that is, in fact, still uncompleted today. It is instructive to compare Seigel's linear and truncated account of this trajectory with Stephanie Coontz's nuanced cyclical analysis in Marriage: A History. Her more fully elaborated presentation shows that autonomous networks were not automatic emanations of bourgeois experience, but the product of a complex dialectic of structural transformation and social struggle. ${ }^{18}$

15 Karl Marx and Friedrich Engels, The Communist Manifesto (New York, 1948; first published 1848), 13. Seigel reaffirms the limited validity of class as a category, $M B L, 23-7$.

16 Stephen Lawrence Kaplan, Farewell Revolution: The Historians' Feud, France, 1789-1989 (Ithaca, 1995); Georges Comninel, Rethinking the French Revolution: Marxism and the Revisionist Challenge (London, 1987); Paul McGarr and Alex Callinicos, Marxism and the Great French Revolution (London, 1993).

17 The literature here is too extensive to cite. In the case of late Victorian Britain, Robert Roberts, The Classic Slum: Salford Life in the First Quarter of the Century (Manchester, 1971); and Standish Meacham, A Life Apart: The English Working Class, 1890-1914 (London, 1977) are good places to start.

18 See MBL, 305-35; and Stephanie Coontz, Marriage: A History: From Obedience to Intimacy, or How Love Conquered Marriage (New York, 2005). 
Many of these deficiencies can be rectified when we conceive of the social structure not as some simple class polarity, in the manner sketched out by the Communist Manifesto, but as a more complex social formation, in which a series of more precisely delineated class fractions (e.g. artisans, unskilled workers, finance capitalists, industrial entrepreneurs, rentiers, functionaries, petty bourgeois) interact with one another and with other social categories that may be defined in racial, ethnic, or gendered terms. As Seigel points out in Marx's Fate, Marx himself made the first move in initiating this type of study, when he shifted from the broad strokes of the 1848 Manifesto to the detailed narrative of The Eighteenth Brumaire of Louis Bonaparte. In Seigel's rendering, this shift was grounded in an implicit recognition that the original "pure" and "transparent" class categories were not working, and did not accurately reflect existing social realities, which were driven by deeper structures, operative underneath. ${ }^{19}$ There is, however, a different way to understand Marx's move, as an effort to relocate his original theory from the highest level of abstraction to one that more accurately and precisely specifies the ways in which society has actually been organized in any specific time/place. While subsequent Marxist theorists have not done nearly enough to develop this more proximate analytic, and to grasp its relation to the ultimate categories of abstract theory, most serious Marxist efforts at empirical investigation or historical interpretation have drawn upon this more nuanced "social-formation" analysis, either explicitly or in implicit terms. ${ }^{20}$

These considerations are especially relevant when we study the class formation and structure of the bourgeoisie. For the bourgeois subjects whom we actually encounter in history almost never appear in "pure" "bourgeois" dress. On the contrary, they present themselves to us first and foremost as members of more determinate class fractions-industrialists, financiers, landowners, small businessmen, bureaucrats, professionals, retailers, etc. The social character, political orientation, and economic significance of these fractions varies considerably from case to case, depending on a multitude of factors, such as the socioeconomic development of the society in question, the residual weight of precapitalist elements, the degree of working-class mobilization, and the

19 Marx and Engels, Communist Manifesto; Karl Marx, The Class Struggles in France, 18481850 (Moscow, 1972); Marx , The Eighteenth Brumaire of Louis Bonaparte (New York, 1963); MF, 193-213.

20 The "structuralist" interpretation of Marxism is elaborated most extensively in Louis Althusser, For Marx, trans. Ben Brewster (New York, 1970), 87-128; and Althusser , Lenin and Philosophy and other Essays, trans. Ben Brewster (New York, 1971), 127-86. The concept of a "social formation" is integrated into structuralist Marxism by Nicos Poulantzas in Political Power and Social Classes, trans. Timothy O'Hagan (London, 1978), 1-98. In my view, however, the analysis is developed most thoroughly by Pierre-Philippe Rey in Les alliances de classes: Sur l'articulation des modes de production (Paris, 1978). 
historical role of the state. ${ }^{21}$ In these circumstances, bourgeois rule is never seamless or automatic, but is cobbled together through shifting coalitions, and is expressed and reproduced through a process of hegemony on which the twentieth-century Marxist theoretician Antonio Gramsci shed considerable light. $^{22}$

Seigel is brusquely dismissive of Gramsci, but offers few reasons for this negative assessment. This is unfortunate, since the issue is obliquely raised and dismissed in a single paragraph. Nevertheless, I am convinced that Seigel's "networks" and Gramsci's "hegemony" are natural correlates that might prove mutually beneficial. The latter offers a compelling account of the way in which subordinated classes and class fractions acquiesce in their subordination, although it runs the risk of descending into an indictment of "false consciousness" when "hegemony" is construed as the repudiation of class interests in any simple sense. But "false consciousness" has no legitimate place in a Marxism that has been refracted through the lenses of "social formation" and Gramscian "hegemony." Since bourgeois hegemony is always engineered by a coalition of more specific capitalist fractions, it is necessary not only that they look beyond their own narrow sectional interests, but also that they couch their class rule in the guise of a broad universalistic vision that takes into account the interests of at least certain sectors of the working class. Inasmuch as some workers are always (at least partly) accommodated within any successful bourgeois hegemonic formation, we should not be surprised to find them taking advantage of network opportunities initiated by the bourgeoisie. It is therefore only reasonable that those who achieve high levels of network integration should exhibit forms of consciousness and behavior that comport well with Seigel's culture of "bourgeois life."

At the same time, Seigel's analysis could be considerably fortified by taking on board the Gramscian approach to hegemony. This will help us to understand why worker (or aristocratic) integration into "bourgeois" networks is usually partial and contingent, and shows its robust face only when the networks can be made

${ }^{21} \quad$ For an example of an empirical historical study written along these lines see my own Class Formation and Urban Industrial Society.

22 On Gramscian "hegemony" see Antonio Gramsci, Selections from the Prison Notebooks, ed. and trans. Quintin Hoare and Geoffrey Nowell Smith (New York, 1971), esp. 229-39; and David Forgacs, ed., The Antonio Gramsci Reader (New York, 2000), 189-221. See also Perry Anderson, “The Antinomies of Antonio Gramsci," New Left Review 100 (19767), 5-78; Geoff Eley, "Reading Gramsci in English: Observations on the Reception of Antonio Gramsci in the English Speaking World, 1957-82," European History Quarterly 14 (1984), 441-78. My own approach to making Gramscian "hegemony" operational as a historiographical tool can be found in Theodore Koditschek, "The Possibilities of Theory: Thompson's Marxist History," in Roger Fieldhouse and Richard Taylor, eds., E. P. Thompson and English Radicalism (Manchester, 2013), 70-95. 
to correspond with other, more collective, less open-ended forms of solidarity. In such instances, what we find is not so much an abandonment of class interests, as an ambivalent consciousness that usually reflects the contradictory social location of the groups in question: they have found a way to function efficaciously within the framework of capitalism, yet retain certain value commitments and behavioral impulses that would probably have to be labeled "teleocratic" in Seigel's scheme. There is, indeed, a certain danger when one contrasts the mentality of open networks with that of teleocratic constraints to fall into a simple celebration of bourgeois culture, or to equate it with the spread of autonomy and freedom tout court. Seigel, of course, does not fall into this vulgar error. However, in less sophisticated hands, his approach to "modernity" might be misconstrued in this way. The injection of Gramscian "hegemony" into his analysis would be a prophylactic against this distortion.

\section{IV}

This type of mixed theoretical perspective that seeks to reconcile Seigel with Marx and Gramsci would likely prove to be particularly indispensable in understanding our own contemporary capitalist society, since it has become clear that class interests are never the sole factors in determining the identity or consciousness of most individuals. At the same time, it is equally clear that class distinctions remain a central (and perhaps intensifying) feature of our present socioeconomic system, and that the cultural and political consciousness they generate will also not go away. Our world is filled with people who are simultaneously exploited in the market- or workplace, and effectively integrated into religious, ethnic, political, or informational networks that are likely to shape their response to capitalist exploitation in nonmaterially inflected ways. Fifty years ago, a culture of means had developed through left political parties, trade unions, and a redistributive state that channeled significant resources into the hands of (mostly) white working men in the leading Western countries. These working people were bonded to the system (and to one another) in thoroughly modern, and yet still solidaristic, communitarian ways. ${ }^{23}$

Today these solidaristic institutions have been greatly weakened, and it is largely in networks of cultural connection that their residue has been retained. Unlike the old institutions, networks of this type are potentially open to many other subaltern groups-minorities, women, gays, and postcolonials in the developing world. The benefits they provide are real and important, but they

23 Once again, where Seigel sees networks, I would emphasize institutions as central to what made possible the integration of the white male working class into mid-twentieth-century Euro-American capitalist society. 
are more likely to be symbolic and informational than material and economic. It does not necessarily make one an economic determinist to admit that such symbolic or informational resources will provide little practical benefit to those without secure access to market opportunity or the material necessities of life. In principle, of course, there is no reason why such informational goods cannot be infinitely multiplied. Yet, because they are often tied to quests for identity, they tend in practice to devolve into zero-sum games. Because identity is most effectively formed in opposition to some feared or hated other, such cultures of means often thrive in a spirit of mutual antagonism. The strengthening of identity on the part of any one group is likely to be perceived as a threat by the others, and vice versa. ${ }^{24}$ The result, which can be seen on a daily basis in any newspaper, is a toxic politics of bigotry and vituperation that degenerates, at its worst, into full-scale interethnic conflict or holy, religious war.

As Seigel notes in his conclusion to Modernity and Bourgeois Life, the advent of the Internet and social media have drastically amplified the chains of connection by which these often antithetical cultural and informational networks have been able to proliferate and therefore collide with one another. Moreover, the results (as was the case with earlier, less extended networks) have not always been to enhance the agency and autonomy of those who are drawn up in networked life. As with earlier media, digitization has also enhanced opportunities for state control and surveillance, while much of the Internet has been colonized by commercial corporations that are mainly interested in making profits, collecting user information, and stimulating consumer desire. Like the democratic parties of the late nineteenth century, the virtual identity communities of the twentyfirst century might begin as spontaneous mass movements, but they are easily hijacked by political operatives with ideological agendas, who are quite adept at using digital information to shape the opinion of those demographic groups that fall under their sway.

As in the later decades of the nineteenth century, the dynamic of capitalism today tends to foster a massive trend towards economic inequality. ${ }^{25}$ As the top one percent evolves into an ever more advantaged and entitled elite, it is not surprising that the Internet and identity networks of contemporary cyberspace (populated by those below them) become filled with a sense of betrayal and inchoate rage. Absent cogent diagnoses of capitalism's contradictions and dysfunctions, and in lieu of rational programs by which deep-seeded grievances might be redressed, we are surrounded by such diverse and incompatible responses as ISIS and Brexit

24 For a classic historical account see Linda Colley, Britons: Forging the Nation: 1707-1837 (New Haven, 1982).

25 Thomas Piketty, Capital in the Twenty-First Century, trans. Arthur Goldhammer (Cambridge, MA, 2014). 
across the Atlantic, or Donald Trump and Bernie Sanders in the United States. Consider the typical white, male Trump voter: fifty years ago, his counterpart would have belonged to a trade union, voted for Democratic New Deal politicians, and felt a prideful stake in the reformed capitalism of that age. Today, he is more often fixated on the loss of this relatively privileged position, and is outraged to find that he must assert his own aggressive identity claims amidst a cacophony of antithetical voices that harangue him from inescapable screens: "Black Lives Matter," "Save the Environment," "End Sexual Harassment," or "We're Here and We're Queer." When bombs explode in Paris nightclubs he does not consider how they might have been precipitated by drone strikes in Syria. Since such chains of connection are not on his radar, he sees them only as assaults on his own way of life. Exchanging double measures of outrage and demonization with like-minded fellows, he sets the circuits of his network ablaze.

Certainly, none of these outcomes were predicted by Marx and Engels, though they are also not the scenarios that we would anticipate from the thrust of Seigel's work. For here, we seem to see an explosively expansive culture of informational means that is fueled by its participants' perceptions of the socioeconomic means that they lack. That said, the triumph of reaction is not necessarily the way of the future, and contrary trends can be discerned amidst the complex cross-currents of our day. In his most recent book, Between Cultures, Seigel traces the lineaments of a very different response to the antinomies and complexities of a multicultural world. Through the lives of five leading intellectuals, at work between the $1850 \mathrm{~s}$ and the present, he explores the efforts of these individuals in "opening up a real or imagined space between cultures," in order to create the possibility of "inhabit[ing] more than one culture at the same time." In particular, "each [of these five men] sought to bridge some explicitly European identity with a persona rooted in another part of the world" $(B C, 1-3)$.

In our emerging era of global capitalism, this transcultural impulse will almost certainly become one of the central imperatives of twenty-first-century bourgeois life. It is probably the only form of identity that can constructively correspond to socioeconomic reality and build bridges with others, rather than wallow in angry, mutually destructive reaction. For those with the requisite chains of connection and networks of means, opportunities to follow such paths of selfdevelopment may indeed lead to new frontiers of personal autonomy and cultural enrichment, as are foreshadowed by the exemplary figures Seigel examines in his latest book. However, for those who find these opportunities for cultural hybridity foreclosed through class disadvantage or cultural impoverishment, the future looks extremely bleak. The old teleocratic universe is gone forever, and quasi-autarkic local communities are beyond revival. In stark contrast to the eras of classic liberalism and Marxism, the promise of new, integrative forms of modernity can no longer be taken for granted as historical inevitabilities. 
It is for this reason that we need Seigel's sensitive inquiries into the fragile, uncertain contingencies by which such outcomes may be at least partly realized by innovative networkers. But these accounts also need to be supplemented by studies of the structural forces that load the dice in favor of, or against, their creative efforts. Such networks, moreover, are never the work of individuals alone. Mindful of the limitations of the older historiography of class agency, we also need fresh inquiry into those collective movements that will be necessary to bring transcultural action and identity to fruition. Seigel's particular brand of intellectual/cultural history is better designed than any I know to build connective chains with the social and economic historians who also study such matters. His work can make an indispensable contribution to forging the network of means that the historical profession requires in our time. 